\title{
Is Waking just a Different Mode of Dreaming?
}

\author{
Kurt Forrer* \\ 26 Parkins Reef Road, Maldon Victoria 3463, Australia \\ *Corresponding author: Kurt Forrer, 26 Parkins Reef Road, Maldon Victoria 3463, Australia
}

\begin{tabular}{|c|c|}
\hline ARTICLE INFO & ABSTRACT \\
\hline Received: 㓞April 16, 2021 & $\begin{array}{l}\text { Citation: Kurt Forrer. Is Waking just a Different Mode of Dreaming?. Biomed J Sci \& Tech } \\
\text { Res 35(2)-2021. BJSTR. MS.ID.005680. }\end{array}$ \\
\hline
\end{tabular}

\section{Commentary}

\section{Reality in Waking}

Generally, we have no doubt that the waking world is real. But can something transient be real? Can the river that is never the same be real? Is empirical science deluded when it considers processes to be real? Since the oasis in the sky is seen as an illusion, why not the drifting sands?

\section{Reality in Dreaming}

While dreaming we consider it to be a real occurrence. When we wake up, we say, "It was only dream", implying that it was just something transient. Waking is no less transient, yet we apply a different ruler to it. Are there two kinds of reality? Are both states equally real or unreal?

\section{Vision in Waking}

The visual cortex at the back of the head integrates the process of vision. If damaged, blindness can occur even if the eyes are sound. Lesions to different parts of the visual cortex can disrupt the perception of colours or the sensation of motion and the like.

\section{Vision in Dreaming}

The visual cortex is active both in waking and in dreaming, bringing dreaming and waking on common ground, essentially differing only in as much as waking is an apparently outward projection while dreaming is creating an inner space. The posterior cortex, when stimulated during wakefulness induces a feeling of being in a parallel world or in a dream-like state. These regions seem to offer a multi-sensory integration, which is well-suited to support the virtual simulation of a world, characterising dreams.

\section{Spatial Experience in Waking}

The superior lobule and inferior parietal lobule are the primary areas of body or spatial awareness. A lesion in the right superior or inferior parietal lobule leads to hemineglect. This effaces awareness to one side of the field of vision. Such failure of partial awareness must remind us that the reality of space is dependent on a particular brain function. In other words, there is no 'space as such'. Space is not an object. It is an entirely subjective experience, just as the rest of the waking world is.

\section{Spatial Experience in Dreaming}

French research reports show that the most striking feature of conscious experience in sleep is how altogether similar the inner world of dreams is to the real world of wakefulness. It maintains that in most dreams, the perceptual modalities and sub-modalities that dominate wakefulness are heavily represented. The same study also highlights the fact that there is a remarkable consistency between a subject's cognitive and neural organisation in waking and dreaming. Studies of children, for instance, demonstrate that 'dream features show a gradual development that parallels their cognitive development when awake'.

\section{Imagination}

Dreaming, especially daydreaming is closely related to imagination, so we would expect the visual cortex to be involved. "Recent work in neuroscience has focused on mental representations instead of operation, showing that the contents of visual perception, visual imagery, and even dreams can be decoded from activity in (the) visual cortex. These results suggest that the 
same regions that mediate representations in sensory perception are also involved in mental imagery".

\section{Daydreaming}

Rosalind D. Cartwright's experiment on REM rebound shows that substituting an interrupted REM episode by means of mathematical activity will result in REM rebound while the subject that is woken at REM and is allowed to compensate the REM loss awake by means of his imagination, will evidence no REM rebound. What strikes us here first is that REM dreaming can be replaced by fantasy or indeed, daydreaming. However, we need to take heed of the fact that this 'daydreaming' springs from the memory of a fragment of the dream that has gone ahead. Keeping this in mind is extremely important, for it leaves the door open to the idea that the REM process in the fantasy substitution had not really been halted but was instead simply shunted into the waking sphere.

\section{Schizophrenia}

Rosalind Cartwright remarks on the predicament of the schizophrenic that "every dream in the night of a schizophrenic sounds like one from the first REM period. A problem is stated, but something prevents the development of more complicated dreams that ordinarily takes place as REM periods become longer. There is no continuity of theme from REM to REM across the night; dream thought is as disorganized as waking thought." This lack of REM development is then compensated during the day by dreamlike activity erupting into daytime thought. This switching from REM dreaming to apparent waking episodes of the night and its reversal during the day could hardly be better evidence of the principal identity of dreaming and waking.

\section{Somnambulism}

During REM the body is flooded with two chemical secretions that paralyse it. If we wonder why Mother Nature has established this mechanism, we only need to look to the somnambulist who gets up to act out his dreams, so robbing him of proper rest and endangering his life and that of other people. That there can be little doubt about this is demonstrated by the fact that when a nonsomnambulistic subject is playing tennis in his dreams, there is a higher electrical charge in his racket hand.

It is not a little astonishing that among dream researchers there is still largely a question mark hovering over the function of the dream when the somnambulist so palpably and indeed, dramatically, demonstrates its purpose.

\section{Déjà Vu}

The curious impression that we have experienced or seen something before has a number of explanations: a glitch in the brain, something encountered in a past life, coincidence. The last of these comes close to the truth, however not in the sense of haphazard coinciding, but of purposeful coming together: the coming together of a dream memory and its manifestation. 'You've broken my dream' is a variant of the déjà vu. Premonitions too, are in this category with one difference: the dream underlying it is recalled only cryptomnesically.

\section{Posthypnotic Suggestion}

Like the somnambulist, the hypnotised subject will execute what his 'dream command' had requested of him. There is a difference, however, between the action of the two actors insofar as the somnambulist manipulates the objects of the waking world, seeing only the corresponding objects of the dream world, while the hypnotised subject manipulates the objects of the waking world as they are seen in that realm, yet remaining unable to recall them as perceived in his 'dream'. Both cases show how dreaming and waking smoothly mesh although they appear to be utterly separate realms.

\section{Lucid Dreaming}

For some lucid dreaming is particularly fascinating since it allows the dreamer to create his own environment. In lucid dreaming acts and situations are possible which have no place in ordinary dreams or in waking. This seems to be the result of a mixture of two states combined. Lucid dreaming is based on an ordinary dream with the inclusion of waking functions. Thus, the dream provides the basis of operation while the waking functions provide it with the direction of the action. The result is delightful to the lucid dreamer, but it does not translate into waking reality, which adds up to extreme disappointment.

\section{Conflict of Interests}

None. 
ISSN: 2574-1241

DOI: $10.26717 /$ BJSTR.2021.35.005680

Kurt Forrer Biomed J Sci \& Tech Res

(c) (P) This work is licensed under Creative BY Commons Attribution 4.0 License

Submission Link: https://biomedres.us/submit-manuscript.php

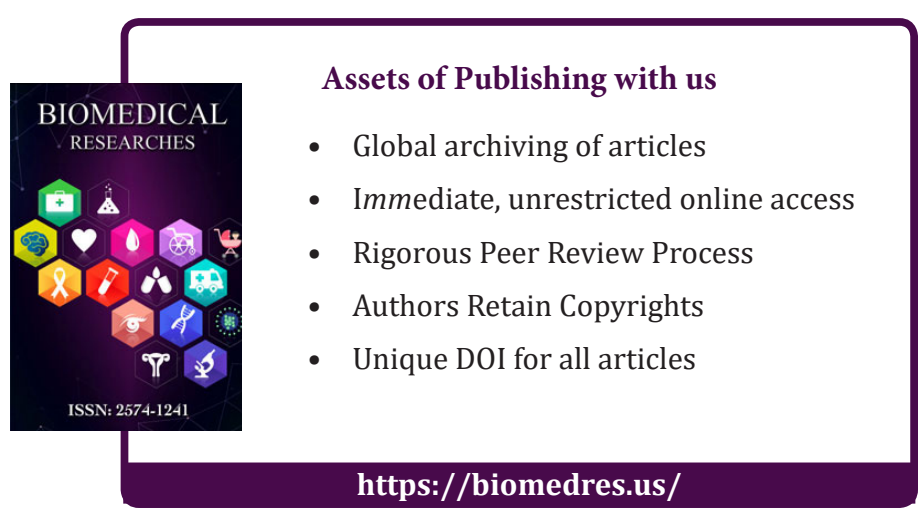

